\title{
From the Hobbes-Parsons Problem to a Non-Linear Dimensionalist Model of Cultures
}

\author{
Christian Etzrodt \\ School of Human Sciences, Osaka University, Osaka, Japan \\ Email: etzrodtc@hotmail.com
}

How to cite this paper: Etzrodt, C. (2020). From the Hobbes-Parsons Problem to a Non-Linear Dimensionalist Model of Cultures. Sociology Mind, 10, 35-53. https://doi.org/10.4236/sm.2020.101004

Received: November 14, 2019

Accepted: January 11, 2020

Published: January 14, 2020

Copyright (C) 2020 by author(s) and Scientific Research Publishing Inc. This work is licensed under the Creative Commons Attribution International License (CC BY 4.0).

http://creativecommons.org/licenses/by/4.0/

\begin{abstract}
The aim of this paper is to reconceptualize the classical problem of social order in Thomas Hobbes and Talcott Parsons by utilizing the tool of game theory, and thereby to formulate its motivational and institutional solutions as the basis of a theoretically guided construction of major cultural types. An analysis of the social-order problem shall be presented based on the insight that three aspects (the nature of the cooperation problem as well as motivational and institutional solutions) of Hobbes's and Parsons's approach are important. Finally, the three motivational solutions (habits, morality, and altruism) can be combined with the three institutional solutions (rituals, markets, and bureaucracies) in order to form three ideal-types of cultures (one traditional and two modern types), which allows the perception of different types of modernities.
\end{abstract}

\section{Keywords}

Talcott Parsons, Thomas Hobbes, Social-Order Problem, Dimensionalist Cross-Culture Studies, Prisoners' Dilemma

\section{Introduction}

The aim of this paper is to reconceptualize the classical problem of social order in Thomas Hobbes and Talcott Parsons with the help of game theory, and thereby to formulate its motivational and institutional solutions as the basis of a theoretically guided construction of major cultural types. It is not my aim here to provide an authoritative interpretation of Hobbes' and Parsons' works. My reading of Hobbes and Parsons is rather selective. The proposed synthesis of their works is the starting point for the development of a model that allows empirical tests of different hypotheses as for example that all cultures are following the same path of development as the United States (Parsons) or that Japan has a 
unique modern culture that emphasizes the importance of the group (nihonjinron).

This approach is related to dimensionalist cross-cultural studies which try to find "the ultimate, most frugal, and yet most meaningful basic set of axes with which to explain the broad range of attitudes, beliefs, lifestyles and the diversity of practices among large populations and/or organizations across societies" (Vinken et al., 2004: p. 8). My problem with many of these studies is however that they were developed in a non-sociological context. Hofstede's (2001) study and the GLOBE study (House et al., 2004) focused on economic dimensions like for example uncertainty avoidance or leadership attitudes. Harry Triandis (1989) and Shalom Schwartz (1992) developed their approach from a psychological point of view. And Ronald Inglehart (1990) was interested in the contrast of materialist and postmaterialist values, which are relevant for political science. In contrast, I will derive dimensions in this paper that are relevant for sociology.

\section{Hobbes: Exchange of Freedom for Security}

Based on his experience of the English Revolution, Hobbes developed the concept of the "state of nature" in the sense of the absence of order as war of all against all. This state is characterized by "continual fear, and danger of violent death," where the people's life is "solitary, poor, nasty, brutish, and short" (Hobbes, 1839: p. 113). In this "state of nature", every person has the "right of nature" to do everything that is necessary for the preservation of his own life (Hobbes, 1839: p. 116), even if this means violating the rights of somebody else (Gauthier, 1979: p. 549). The "right of nature" is basically immoral (Gauthier, 1979: p. 550). However, it is not the "right of nature" which causes the war of all against all, but rather the unrestricted passions and desires for gain, safety, and glory (Hobbes, 1839: p. 112; Raphael, 2004: p. 20). Every person has the same risk of being killed, because the natural equality of human beings makes it impossible for one person to dominate all others (Hobbes, 1839: p. 110; Voss, 1985: p. 39). This fear of death should motivate the development of "right reason" (cf. Ball, 1985: p. 748), which demands the acceptance of the "laws of nature", "which declare unto us the ways of peace, where the same may be obtained, and of defence where it may not" (Hobbes, 1969: p. 75; cf. 1839: 147).

The difference between the "right" and the "laws of nature" is important. The right describes the actors' liberty in the "state of nature," whereas the laws describe their obligation to keep the peace as long as their own life is not threatened (Hobbes, 1839: p. 117). As for "right reason"-based on the rule of treating others as you wish to be treated by them (Hobbes, 1839: pp. 118-144, 1841: p. 45; Kavka, 1983b: p. 123) -let us conclude that keeping the peace is an obligation in our own interest, as "we ought to take our medicine when we are sick," because "both actions are necessary causes of desired effects" (Hampton, 1992: p. 338). Therefore, the fear of death in the "state of nature" can be overcome by reasonable actors, who will agree to form a social contract in order to create a state which will produce social order and security (Schmitt, 1937: p. 622; Alexander, 
1971: p. 33; Forsyth, 1994: p. 43; Hobbes, 1839: p. 116). The social contract is a voluntary transfer of my "right of nature" to govern myself to a chosen man or assembly of men (Hobbes, 1839: p. 158; Oakeshott, 1946: p. 40) in exchange for protection and security (Taylor, 1938: p. 417).

However, the problem with Hobbes's solution to the social-order problem is the concrete content of the "right reason" argument. Hobbes provided a theory of motivation for the "state of nature", which he seems to abandon in favor of a theory of obligation after a social contract is formed. The human nature described in the theory of motivation is utilitarian (Hobbes, 1839: p. 41, 1841: p. 3; Warrender, 1962: p. 447), egoistic (Gauthier, 1979: p. 549; Kavka, 1983a: p. 293; Watkins, 1955: p. 136f.), and based on instrumental reasoning (Gauthier, 1969: p. 77). Hobbes's actor in the theory of motivation can be characterized as the utility-maximizing homo oeconomicus (Watkins, 1955: p. 138; Gauthier, 1979: p. 549). But based on these assumptions it is no longer possible to explain the "state of nature" (civil war) and the existence of a social order as rational. If cooperation is rational, then civil war must be irrational (Strauss, 1950: p. 430; Kateb, 1989: pp. 355, 357). And if on the other hand civil war is rational, then to keep one's word and to obey the laws must be irrational (cf. Kavka, 1983b: p. 120). It is therefore an open question as to what the basis of "right reason" is in the theory of obligation. Several interpretations are given in the secondary literature:

1) "Right reason" as a responsible long-term maximizing strategy in contrast to passionate shortsightedness (Hampton, 1985: pp. 53, 56; cf. Hood, 1964: p. 66): "because men cannot put off this same irrational appetite, whereby they greedily prefer the present good (to which, by strict consequence, many unforeseen evils do adhere) before the future" (Hobbes, 1841: p. 48). Short-term considerations in the theory of motivation are replaced by long-term considerations in the theory of obligation.

2) "Right reason" as a dispositional choice (Gauthier, 1979: p. 547f.; cf. Kavka, 1983b: p. 126f.) of the best alternative in the long run (Gauthier, 1979: p. 551; cf. Hampton, 1992: p. 337). The theories of motivation and obligation are only distinguished by case-by-case decisions in contrast to one decision for all future cases.

3) "Right reason" as an other-directed utility calculation-which I will call altruism-in contrast to "reason in the sense of self-concentrated calculation" (cf. Forsyth, 1994: p. 43): "By right reason [...] I understand [...] the [...] true ratiocination of every man concerning those actions of his, which may either redound to the damage or benefit of his neighbours" (Hobbes, 1841: 16n.). The distinction between motivation theory and obligation theory is here the difference between egoistic and altruistic utility maximization.

Hobbes's contribution to the social-order problem is the idea of social order as a result of a social contract of rational actors and not as a divine order that paves the way for a sociological analysis of the actor's motivation to cooperate. His assumption of shortsighted egoistic case-by-case utility maximizing actors in 
the "state of nature" defines the worst case and the problem which has to be solved in this sense. And he anticipates that an explanation of social order cannot rely on purely egoistic utility maximization, which implies that at least one of the three assumptions of shortsightedness, egoism, or case-by-case choices has to be replaced.

\section{Parsons: Free Choice of Socialized Individuals to Cooperate}

Like Hobbes, Talcott Parsons (1902-1979) was confronted with the problem of explaining the existence of social order. But in contrast to Hobbes, Parsons was not dealing directly with political questions in his discussion of the social-order problem. He focused instead on theoretical questions. Parsons wanted to construct a theory that can explain the stability of a social order, without the need to abandon self-interested and free actors (Skidmore, 1975: p. 155).

Parsons started in his voluntaristic theory with instrumentally rational actors. But instead of assuming a "state of nature" as Hobbes did, he stated that these actors are born into a society with an existing value system and culture. In their youth, these actors internalize the culture and values of their society, which then guide the actors' self-interest into culturally determined value-attitudes (Parsons, 1951: p. 211). And because the individual interests and the group interests are identical under these conditions, the actors want to do what they ought to do (Goode, 1960: p. 251; cf. Kassab, 1991: 13f.; Alexander, 1983: p. 41, 1990: p. 4; Wenzel, 1986: p. 21).

Parsons solved Hobbes's social-order problem by changing his assumptions about human nature. Hobbes assumed egoistic atomistic individuals with inborn passions. Parsons on the other hand argued that human nature shows a great plasticity and that no specific motives are naturally given (Parsons, 1986: p. 180). This transforms Hobbes's original problem of how a war of all against all can be avoided in a world full of egoists into the question of why self-interested actors are willing to cooperate voluntarily (cf. Münch, 1982: p. 12). And Parsons's answer is "culture" (cf. Lockwood, 1956: p. 137).

Culture is the solution to the fundamental discrepancy between individual interests and collective requirements (of the social system), as long as the cultural system produces an effective role-system that is successfully institutionalized into the social system and internalized into the personality system of the individuals (Joas, 1973: p. 28; Zeitlin, 1973: p. 21). The institutionalization of the social values into the social system is a kind of back up for an imperfect socialization. Deviant behavior will occur as a result of socialization failures. The social system has the function of benefiting rule-following behavior and sanctioning deviant behavior (Parsons, 1951: p. 230). Parsons, therefore, adds a second solution. The actors pursue not only collective aims, because they have internalized the preference for rule-following behavior (Parsons, 1951: p. 211), but also because they want to avoid sanctions (Parsons, 1951: pp. 31, 38). The contradiction between individual and collective interests can be bridged if culture leads to a conver- 
gence between the needs of society and individual preferences. Internalized values and institutional role patterns must be functionally consistent with the requirements of the society (cf. Parsons, 1951: p. 227).

In summary, Parsons's solution to Hobbes's problem of the existence of a stable social order is a combination of two completely different explanations-a theory of institution and a theory of motivation. The social order is ensured, if:

1) The cultural value patterns produce institutions with role systems, which guarantee the functioning of a sanction system;

2) The cultural values and institutional sanction system motivate the actors to play the given roles (Zeitlin, 1973: p. 24; cf. Parsons, 1951: p. 230). The motivation for role-conforming behavior is again ensured, if:

a) Sanction-optimizing actors have to expect sufficient institutional (external) sanctions for deviant behavior (Parsons, 1951: 5f., 59) in order to make cooperation the more attractive alternative for the individual actor; and if

b) The actors internalize the cultural values and form an internal sanction system in the sense of a guilty conscience (Parsons, 1986: p. 105) - which I define as moral behavior. If the moral rules are accepted as categorical imperatives, then the actors will follow the rules unconditionally without considerations about costs (feelings of guilt) and benefits of the violation of their morality (cf. Münch, 1982: p. 30).

Therefore, social control and self-control are the two parts of Parsons's theory of motivation (Parsons, 1951: 31, 38). However, Parsons gave priority to the moral restrictions and the internal sanction system (Parsons, 1986: 169f.; cf. 1951: 64). The element of social control is only supplementary. The deficiencies of the socialization system and the effect that not every actor will internalize the cultural values perfectly into categorical imperatives require an external sanction system (Parsons, 1951: p. 321). The institutions function as a security belt to imperfect socialization processes (Parsons, 1951: p. 230). In contrast to Hobbes's theory, the execution of the normative sanctions is unproblematic for Parsons, although it might represent a high risk for the sanctioning person, because actors who have the categorical imperative to sanction deviant behavior will punish uncooperative behavior regardless of the possible costs.

Parsons's contribution to Hobbes's problem is the important insight that not only a theory of motivation is needed to explain the stability of social order, but that also a theory of institution is necessary. The institutional structure must match the needs of the social group and must support the actor's motivation to conform to the social roles. The dependency of the actor's aims and preferences on the cultural values of his social group is a second important point. A third point worth noticing is that Parsons's moral behavior in the sense of an advanced version of Weber's value-rationality is a solution for the social-order problem in his theory of motivation.

\section{Synthesis of Hobbes's and Parsons's Solution}

Before Hobbes the social order in a society was regarded as given by God. Hobbes 
replaced in his theory divine-given order with a natural order (cf. Murphy, 1997: p. 374). Reason took the place of faith and instead of God's will, he was analyzing the natural condition of humanity. Talcott Parsons on the other hand replaced Hobbes's natural order with a culturally given order. Instead of the "state of nature" he was exploring the "state of culture". Hobbes's radicalism in neglecting the influence of traditions was necessary to free the analysis of social order from religious aspects. For Parsons on the other hand such radicalism was no longer needed, because religion no longer played such an important role in the social sciences of his time. Parsons's problem was quite different. He was confronted with the problem of establishing sociology as a social science independent from economics. Therefore a specific sociological explanation of the social-order problem in contrast to an economic explanation based on egoistic utility maximizers was necessary. And his solution was the introduction of culture.

The differences between Hobbes and Parsons can be described in Table 1. Regarding the "nature of humanity", Hobbes developed his theory of motivation. For him, actors are characterized in the "state of nature" as shortsighted, egoistic case-by-case utility maximizers. Parsons does not discuss this point extensively. For him, actors are shaped by the culture of their social group. His theory of motivation is in this sense not related to "nature" but to "culture". Parsons solved the social-order problem (on the individual level) by assuming that actors optimize sanctions and internalize cultural values (formally this is equivalent to a dispositional moral choice). Parsons's theory of motivation is related to Hobbes's theory of obligation, although it is not entirely clear how Hobbes's theory should be interpreted. The different interpretations suggest three possible solutions: long-term maximization instead of shortsightedness, a dispositional moral choice instead of case-by-case maximization, or altruism instead of egoism. Additionally, Parsons proposed a theory of institution to emphasize the requirement of the internal consistency of the different institutions for a sufficient motivation for role-conforming behavior. Nothing equivalent exists in Hobbes's works. Hobbes did not formulate a theory of institution, but he did anticipate the importance of institutional arrangements. For example, absolutism was for him an institutional solution to the competence struggle in the English revolution between the king and the English parliament. This is a solution that meets the functional requirements of the social system, as Parsons would have formulated it.

In the following, I shall combine these two approaches. I shall start with Hobbes's theory of motivation in the "state of nature", but I will analyze the situation instead of the motivations. The task is to analyze the "nature" of the cooperation problem in interactions and not to examine the "nature" of isolated and pre-socialized individuals. The next step will be a motivation analysis comparable to Hobbes's theory of obligation or Parsons's theory of motivation. This embodies the question of which motives can solve the interaction problem on the social actor's level. And finally, I will use Parsons's insight into the relevance 
Table 1. Comparison of Hobees's and Parsons's solutions to the social order problem.

\begin{tabular}{|c|c|c|c|}
\hline & Hobbes & Parsons & My Analysis \\
\hline Nature & $\begin{array}{l}\text { Theory of motivation } \\
\text { (shortsighted egoistic case-by-case } \\
\text { utility maximizers) }\end{array}$ & $\begin{array}{l}- \\
\text { e(Culturally shapeable } \\
\text { utility maximizers) }\end{array}$ & $\begin{array}{l}\text { Situation analysis } \\
\text { (what is the problem in the } \\
\text { interaction structure) }\end{array}$ \\
\hline \multirow[b]{2}{*}{ Culture } & $\begin{array}{l}\text { Theory of obligation } \\
\text { 1) Long-term maximizers } \\
\text { 2) Dispositional choice } \\
\text { 3) Altruism }\end{array}$ & $\begin{array}{l}\text { Theory of motivation } \\
\text { 1) Sanction optimizers, } \\
\text { 2) Dispositional choice }\end{array}$ & $\begin{array}{l}\text { Motivation analysis } \\
\text { (which motives can solve } \\
\text { the interaction problem) }\end{array}$ \\
\hline & $\begin{array}{l}\text { (Absolutism as an institutional } \\
\text { solution) }\end{array}$ & $\begin{array}{l}\text { Theory of institution } \\
\text { (internal consistency of the } \\
\text { system with the aim of } \\
\text { providing a sufficient } \\
\text { motivation for the actors) }\end{array}$ & $\begin{array}{l}\text { Institution analysis } \\
\text { (into which institution can } \\
\text { the interaction problem be } \\
\text { transformed) }\end{array}$ \\
\hline
\end{tabular}

of institutional arrangements for the social-order problem and proceed to an institution analysis.

\section{The Synthesized Approach}

\subsection{Situation Analysis}

The situation in relation to the social-order problem-where individual and collective interests contradict each other-is most commonly described by modern interpreters of Hobbes's war of all against all others as a prisoner's-dilemma game (Gauthier, 1969: 77ff.; Rawls, 1971: p. 269; Taylor, 1976: 101ff.; Kavka, 1983a: 299ff.; Hampton, 1985: p. 51; Barry, 1990: 253f.). The prisoner's dilemma is a symmetrical game between two equivalent players (see Table 2). Both players have a choice between a cooperative and an uncooperative strategy (the first number represents the outcome of the first player, whereas the second number stands for the second player's result). If both choose the cooperative strategy, the best outcome for the group can be achieved. But it is not the best individual result each player can receive. In fact, every player has a very strong incentive to choose the uncooperative strategy, because, independently of the opponent's choice, the uncooperative strategy is always better ( 5 is higher than 3 , if the opponent plays cooperatively, and 1 is higher than 0 , if he is uncooperative). Under the assumption that players are individually rational-which I define throughout the paper as the application of the Nash strategy-and shortsighted egoistic case-by-case maximizers, we should, therefore, expect the lowest outcome for the social group.

The most important solution for the prisoner's dilemma in game theory is the iteration of the game. The argument is that actors have the opportunity to sanction uncooperative behavior of their opponents by playing uncooperatively in the following round of the game. Iterations fulfill the function of a sanction system (Voss, 1985: p. 155; Forges, 1992: p. 156). If the actors furthermore only return to their cooperative strategy after the opponents cooperate again, then the advantage for the opponent to play uncooperatively vanishes in the long run. However, this 
Table 2. A prisoner's dilemma game.

\begin{tabular}{lccc}
\hline & & \multicolumn{2}{c}{ Player 2 } \\
\cline { 3 - 4 } & & Cooperative & Uncooperative \\
\hline \multirow{2}{*}{ Player 1 } & Cooperative & $3 ; 3$ & $0 ; 5$ \\
& Uncooperative & $5 ; 0$ & $1 ; 1^{\star}$ \\
\hline
\end{tabular}

argumentation does not solve the problem for finite repetitions of the game. If a game is played only 10 times, then it is not reasonable to cooperate in the last round (because their behavior cannot be sanctioned in the 11th round). But if they have no reason to cooperate in the last round, then they have no reason to cooperate in the 9th game either, and so on.

Iteration can solve the problem, therefore, only if the game is played an infinite number of times. However, even in this case cooperation is only one of the individual rational strategies and not the only rational strategy. Uncooperative behavior is in a meta-game with infinite repetitions still an individual rational strategy (Damme, 1987: p. 164). This result depends furthermore on the assumption that actors value present consumption as highly as future consumption (the discount factor is 1), and that therefore future punishment is a deterrent. Cooperation is only plausible if the actors are not shortsighted. But both assumptions of the infiniteness of the game and of farsighted actors are unrealistic. Infinite repetitions are an unacceptable assumption for the explanation of human behavior, because human beings do not live forever (Holler/Illing, 1996: p. 147). And because they do not live forever, it is very reasonable to assume that older people will have a preference of present consumption over future consumption, because they simply cannot be sure of realizing future expectations. Besides, the real phenomena of tobacco consumption or private debts indicate that human beings are in fact shortsighted. Therefore we can reject long-term maximization as a realistic solution to the prisoner's dilemma (this was Hampton's interpretation of Hobbes's "right reason"). It is, therefore, not possible to explain a stable social order in game theory under the assumptions of egoistic and individual rational case-by-case utility maximizing actors, since the unrealistic additional assumptions (like unlimited life expectations and ascetic actors) cannot be accepted (cf. Baurmann, 1996: 37f., 275). It is important to realize that I do not say that egoists will never cooperate. I only say that real egoists, who are shortsighted case-by-case maximizers and apply a Nash strategy, will not cooperate in a prisoner's dilemma (Binmore, 2007: p. 324, Theorem 11.1). One of these assumptions must be given up in order to be able to explain cooperative behavior.

\subsection{Motivation Analysis}

I will turn now to the motivational solutions. They are based on a rejection of one of the central assumptions made in game theory. The first solution to the prisoner's dilemma gives up the assumption of egoistic actors, as one of the interpretations of Hobbes's "right reason" suggested. Modern economists devel- 
oped the concept of altruism, which assumes that actors take into consideration to a greater or lesser degree the results of their actions on other people (cf. Becker, 1976: p. 819, 1981: p. 173; Collard, 1978: p. 37). Actors not only maximize their own utility function $\mathrm{u}_{1}\left(\mathrm{x}_{\mathrm{k}}\right)$, but also include the opponent's utility function $\mathrm{u}_{2}\left(\mathrm{x}_{\mathrm{k}}\right)$. The degree of altruism varies by the level of the actor's cooperativeness $(\kappa)$ and his willingness to incorporate the utility function of the other player $\mathrm{u}_{2}$ : $\mathrm{V}_{1}\left(\sigma_{\mathrm{ik}}\right)=(1-\kappa) \mathrm{u}_{1}\left(\mathrm{x}_{\mathrm{k}}\right)+\kappa \mathrm{u}_{2}\left(\mathrm{x}_{\mathrm{k}}\right)$, for $0 \leq \kappa \leq 1$. A high level of cooperativeness $(\kappa)$ can solve the prisoner's dilemma (see Table 3; cf. Fender, 1995: p. 125).

All three games in Table 3 are prisoner's dilemmas, but only in game $a$ the egoists perceive the situation as such. The mainly self-interested actors in game $b$ believe the situation to be a chicken game, in which cooperation can be achieved much more easily than in a prisoner's dilemma. And for the altruists in game $c$, which maximize the group outcome by regarding their own well-being to be as important as the other actors' well-being, the conflict of interests disappears (cf. Ballestrem, 1983: p. 3). Here the cooperative strategy also becomes the individual rational choice (Binmore, 2007: p. 12). Complete altruism is not necessary in every prisoner's dilemma $(\kappa=.5)$ in order to perceive it as a game without a conflict between individual and collective interests. Most of the time, the lesser degrees of cooperativeness will have the same effect. Therefore, altruism is the first motivational solution for the prisoner's dilemma. The prisoner's dilemma vanishes because the perception of the situation was changed and not because the interaction structure in the situation was changed.

The second solution to the prisoner's dilemma is Hobbes's and Parsons's argument that the actors' behavior is also influenced by value-rational considerations. Parsons distinguished two slightly different concepts: norms and morality. I define "norms" as role expectations of the group toward an actor. The other members of the group will sanction uncooperative behavior, as long as a nonanonymous situation allows the identification of the deviant actor. The less anonymous the situation is, the more likely it is the actor's behavior sanctioned. Feelings of shame are related to the concept of norms. They arise if the social group is aware of the violation of the rules. Shame can be interpreted as an anticipation of future sanctions. In opposition to the definition of norms, I define "morality" as the internalized values of an actor, as described by Parsons. The actor will sanction himself (feelings of guilt) if he violates his internalized values. The degree of anonymity is unimportant, since other actors are not involved in this process.

Table 3. Solution of the prisoner's dilemma through altruism $(\kappa=.5)$.

\begin{tabular}{ccccccc}
\hline & \multicolumn{5}{c}{ Player 2} \\
\cline { 2 - 6 } Player 1 & \multicolumn{4}{c}{ Game $\mathrm{a}: \kappa=0$} & Game $\mathrm{b}: \kappa=.25$ & \multicolumn{2}{c}{ Game c: $\kappa=.5$} \\
\cline { 2 - 6 } & Coop. & Uncoop. & Coop. & Uncoop. & Coop. & Uncoop. \\
\hline Cooperative & $3 ; 3$ & $0 ; 5$ & $3 ; 3$ & $1 \frac{1}{4} ; 3 \frac{3}{4}$ & $3 ; 3 *$ & $2 \frac{1}{2} ; 2 \frac{1}{2}$ \\
Uncooperative & $5 ; 0$ & $1 ; 1^{*}$ & $3 \frac{3}{4} ; 1 \frac{1}{4} *$ & $1 ; 1$ & $2 \frac{1}{2} ; 2 \frac{1}{2}$ & $1 ; 1$ \\
\hline
\end{tabular}


However, norms cannot explain cooperative behavior if they are not backed up by another motive, because they produce a prisoner's dilemma of the second order. Everybody wants an uncooperative actor to be sanctioned, but nobody wants to risk his own life by sanctioning him. It is individually rational to avoid the risk, although it is in the interest of the group that someone carries out the sanction. Norms can therefore not be regarded as a solution to the prisoner's dilemma. Morality on the other hand is qualified as an explanation for such cooperative behavior (cf. Binmore, 2007: 21f.). However, morality solves the social-order problem unconditionally only in the form of a Kantian categorical imperative, because only the categorical imperative is restrictive enough to rule out even strong situational incentives. The internalization of the moral rule "never violate the social rules" can preclude further utility considerations. A categorical imperative can be regarded as a dispositional choice and replaces the assumption of case-by-case evaluations. Morality in the sense of a categorical imperative is a perfect solution, but most of the time, less restrictive moral rules are as successful in providing a stable basis for the social order. Morality is therefore the second motivational solution for the prisoner's dilemma.

Hobbes or Parsons did not mention a third solution to the prisoner's dilemma. It is based on Alfred Schutz's concept of habits. The idea is that actors habitualize successful interaction patterns in the past and repeat them automatically in similar situations. Therefore they will recognize only one path that will very likely lead to a successful interaction if the environment has not changed. All other alternative paths are not perceived as elements of the choice set. If the actors habitualized the cooperative path in the past, then they will not recognize the situation as a prisoner's dilemma (cf. Skyrms, 1990: p. 128). In this sense also habits replace the assumption of case-by-case decisions. Individual habits are finally the third motivational solution to the prisoner's dilemma. The cooperative "alternative" is simply taken for granted, and therefore not questioned as long as the other actors are also cooperative.

In all, then, three motivational solutions of the prisoner's dilemma can be identified.

1) Altruism: altruists consider the effects of their actions on other people and maximize the outcome of the social group (Hobbes).

2) Morality: moralists sanction themselves (guilty conscience) and therefore prefer the cooperative alternative (Parsons/Hobbes).

3) Habits. habitual actors cooperate because they take the cooperative alternative for granted (Schutz).

By replacing either egoism through altruism or the assumption of case-by-case decisions through habits or by introducing an internal sanction system (morality) it is now possible to explain cooperative behavior in prisoner's dilemmas. The side effect of this solution is that it still can explain uncooperative behavior and therefore the existence of civil wars, if egoistic morally unconstrained actors make case-by-case evaluations of their expected utility. 


\subsection{Institution Analysis}

The first institutional solution is closely connected to the last motivational solution of habits. Alfred Schutz's discussion of the concept of habits did not have the aim of revealing decision strategies of isolated individuals but of solving the problem of intersubjective understanding. Social actors experience typical interaction patterns in social situations. They habitualize these typical patterns and apply them automatically in appropriate (typical) situations. And because all the actors use the typical experiences as a guidance of their behavior as well as a scheme of interpretation of the other actors' behavior, they can understand each other. In other words, interaction patterns habitualized by all actors of a social group are meaningful, because they can be easily understood on the base of the shared subjective experience of typical social situations. Of course, habitualized interaction patterns or rituals - as I want to call this kind of institution-are constructed as a solution of coordination problems (the problem of intersubjective understanding) and not cooperation problems, although they can solve also prisoner's dilemmas. If the typically experienced interaction patterns of a society are of a cooperative nature, then the actors will automatically follow the meaningful path. Their aim is not to cooperate but to act in a way that can be easily understood by their fellow man. Rituals based on habits are therefore the first institutional solution to the social-order problem in the sense of a transformation of the prisoner's dilemma into a taken-for-granted meaningful (and cooperative) life-world.

But institutional solutions - as the result of habitualized cultural patterns-do not need to have the form of a ritual. It is not always the case that an institutionalized role pattern leads to a fixed outcome for both players. The market, for example, is an institution in which the role patterns (for instance, typical trade customs, accepted currencies, and standardized goods and measurements of goods) are fixed but not the outcome of the interaction (the price of the exchanged goods). In the case of the transformation of the prisoner's dilemma of Table 2 into a market, the distribution of the cooperative surplus of 4 (the difference between the cooperative group outcome of 6 and the uncooperative group outcome of 2) is not a priori decided. The distribution of the surplus depends on demand and supply. The players will receive an outcome of $1+\mathrm{x}$ or 1 $+\mathrm{y}$ respectively, with $\mathrm{x}>0, \mathrm{y}>0$, and $\mathrm{x}+\mathrm{y}=4$. Cooperation is individually rational in the market, because the players will necessarily improve their position. However, the cooperative strategy is only rational in the market because the institution of the market itself is taken for granted. The actors will not even consider not cooperating. The difference between the ritual and the market is therefore not the individual motivation to play cooperatively, but the distribution of the cooperative surplus in fixed ratios or in variable ratios as determined by the price mechanism. Markets with habitualized interaction patterns are the second institutional solution to the social-order problem (cf. Kliemt, 1990: p. 67).

In all solutions discussed so far, I have assumed the actors' equality and sym- 
metry. The players had identical and exchangeable positions. I shall now abandon this rather unrealistic assumption and assume instead that one player has more resources at the beginning and is therefore more powerful than the other player. The first player could use his resources to establish a sanction system, which could provide incentives for the second player to cooperate. However, the support of a sanction system is itself a prisoner's dilemma of the second order. But the first player could be motivated to establish a sanction system, despite the fact that not everybody participates in the support of this social order, if he has a stronger interest in a social order than the second player (cf. Olson, 1965: p. 35). And he has very likely a stronger interest, because he could lose more in a civil war. But it would only be rational for him to provide the resources for a sanction system if the benefits (minus the costs for the sanction system) of cooperation exceed the benefits from the uncooperative alternative. This could be achieved for example by installing a distribution rule-in combination with the social order-that guarantees the powerful player the complete cooperative outcome (see Table 4). The sanction system gives the second powerless player a strong incentive to cooperate, whereas the first player is also motivated to cooperate, because he receives the complete cooperative gain. Of course, less unequal distribution rules might also support cooperative behavior in this institution (the first player has to receive more than 5 in order to be motivated to cooperate).

Transformations of the prisoner's dilemma into power-based sanction systems (norms) are the third institutional solution to the problem of social order. Therefore, the three institutional transformations of the prisoner's dilemma are:

1) Rituals. habitualized social interaction patterns are taken for granted, which leads to clearly defined fixed outcomes for the different actors (Schutz).

2) Markets: habitualized trading patterns are taken for granted and the decentralized price mechanism distributes the collective surplus to the different actors (Kliemt).

3) Power-based sanction systems (norms): forced cooperation of the more or less exploited group and a centralized distribution rule which guarantees the powerful actors the complete (or the largest amount of the) cooperative outcome (Olson).

\subsection{Ideal Types of Cultures}

As Parsons stated, motivational and institutional solutions are not independent of each other. I shall discuss in the following which motivational and institutional solutions can be connected to each other. Based on the combinations of

Table 4. Solution to the prisoner's dilemma through a power-based sanction system.

\begin{tabular}{cccc}
\hline & & \multicolumn{2}{c}{ Player 2 (Powerless) } \\
\cline { 3 - 4 } & Cooperative & Cooperative & Uncooperative \\
\hline $\begin{array}{c}\text { Player } 1 \\
\text { (Powerful) }\end{array}$ & Uncooperative & $6 ; 0^{*}$ & $0 ;(5-6=-1)$ \\
\hline
\end{tabular}


these solutions I shall develop a classification of ideal-typical cultures. The first grouping of habits and rituals is quite obvious, since they simply describe the same phenomenon from different perspectives. The concept of habits stands for the individual's taken-for-granted behavior strategies, which were successful in the past. The concept of rituals explains why the individual's taken-for-granted behavior strategies match each other (because they were experienced in successful social interactions in the past). Furthermore, these two concepts can be separated from all other solutions, because they prevent the actors from adapting to environmental changes (the actors assume that the environment did not change as long as the situation does not become problematic). We can therefore conclude that habits and rituals are typical for slowly changing cultures, which I define nominally as traditional cultures.

On the other hand, morality, altruism, markets and sanction systems allow very fast adaptations to changed situations and can be expected to be characteristic of dynamic cultures, which I define nominally as modern cultures. Markets react with great sensitivity to price changes, which represent environmental changes. In centralized sanction systems, rules can be quickly issued in order to match the new situation. And the powerful actors have an interest in changing the rules, because the inefficiency of non-adaptive institutions could weaken their power. Also, the motivational solutions of morality and altruism do not exclude case-by-case evaluations of the situation and lead to the best result under the given circumstances. However, morality can slow the adaptation process, although it cannot halt it. Morality does not remove new opportunities from the actors' awareness-it only makes them more expensive to follow them as long as these new opportunities are recognized as antisocial-but this status as an antisocial alternative can change over time. Altruists on the other hand react instantly to changes in the environment, because they make the best rational choice for the group according to each situation.

But not every combination of these adaptive solutions in modern cultures matches each other. I am proposing to combine markets with morality and sanction systems with altruism based on logical reasons. The four modern solutions can be separated based on a differentiation of the actors' orientations in interactions. The focus on oneself versus the focus on the alter ego distinguishes the solutions of the market and morality on the one hand from sanction systems and altruism on the other. The concepts of normative sanctions and altruism are by definition related to an alter-ego orientation. A prerequisite for altruistic behavior is that an actor knows the preferences of his alter egos, because only under this condition is a maximization of the group's outcome possible. And in the case of normative behavior, the actor pays attention to other people's opinion, because he wants to avoid the sanctions of other people. Therefore, both altruism and sanction systems require an alter-ego orientation in order to solve the prisoner's dilemma. These two solutions can be regarded as characteristic of modern cultures that emphasize strong group relations. 
On the other hand, actors in perfect competitive markets have only an ego orientation, because the isolated actors interact only with the price mechanism. Their individual choice of whether or not to exchange goods at a given price is completely independent of the personal characteristics of an alter ego. They are only concerned about their own outcome and not about other people's opinions. Similarly, the concept of morality has an ego orientation. Even in anonymous situations, the actors will follow their moral rules, although nobody else can see them and sanction them for deviant behavior. In this sense, the opinions of other people do not count for them. They are only concerned about their own opinion of themselves. Once (social) rules and values are internalized, then morality is in contrast to altruism and norms independent of other people. Therefore, morality is grouped together with the market, because the actors rely on individualistic orientations. In contrast to sanction systems and altruism, markets and morality can solve the prisoner's dilemma without any relation between ego and alter ego. These two solutions seem to be typical for modern cultures that emphasize individualistic ideals.

We can therefore define nominally three cultural types: 1) the traditional culture (solving the prisoner's dilemma predominantly through habits and rituals), 2) the modern individualistic culture (based mainly on markets and morality), and 3 ) the modern relational culture (with altruism and a sanction system as the most important explanation for cooperative behavior). These three idealized types of culture are distinguished as follows (see also Figure 1).

These three culture-types do not exist in pure form in reality, but cultures can be classified according to the relative weights of these solutions. The position of a cultural group in the triangle in Figure 1 is the result of the average mixture of the actors' different definitions of the situation (as ritual, market, or sanction system) and their motives for acting cooperatively (habits, morality, and/or altruism).

I will conclude with an evaluation of Talcott Parsons's solution to the social-order problem. Parsons's insight in applying the dual structure of solutions (motivational and institutional) to the problem of social order is indeed the key to an appropriate analysis. I also agree with Parsons that morality can solve the prisoner's dilemma. However, the previous discussion also reveals that Parsons's

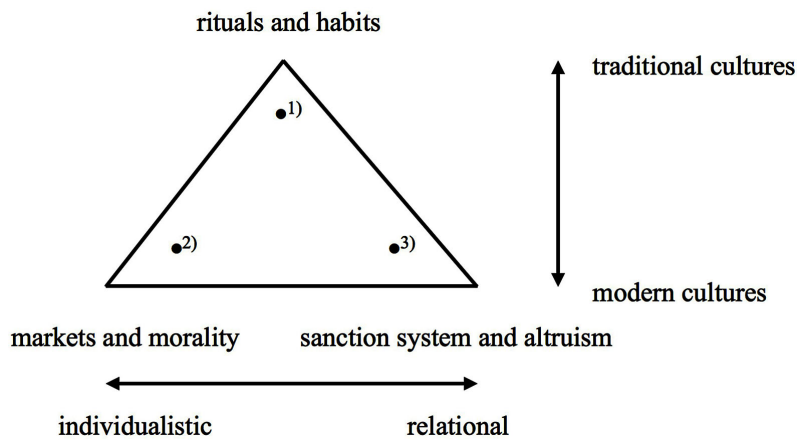

Figure 1. Connection between motives of action and basic cultural types. 
solution to the social-order problem might not be a universal solution. Parsons offered an ethnocentric theory based on American values. He is probably correct in regarding markets and morality as the solution in the United States, but this does not need to be correct for all societies around the world. Parsons admitted that there could exist non-Western solutions to the social order problem. The development of Japan "raises some very broad questions about the future of the system of modernized and modernizing societies." But he weakened this conclusion by stating that Japan "has less built-in stability" than Western countries. And he still seems to equate modern values with economic development, political independence and democracy (Parsons, 1971: 136f.). My proposed model has the advantage over Parsons's model that it recognizes more solutions to the social-order problem, and it therefore does not force the researcher to interpret the heavy reliance on group orientations in Japanese culture as a sign of instability or backwardness, but simply as a different kind of modernity (the key thesis of the nihonjinron about Japanese culture).

\section{Correspondence to Empirical Results}

The result of my theoretical analysis actually corresponds to the empirical findings of the GLOBE study. The GLOBE study is interesting, because in the discussion of individualism and collectivism it regarded collectivism as a multidimensional concept. It distinguished two types of collectivism: In-Group Collectivism, which measured the importance of the family or the primary group, and Institutional Collectivism, which measured the importance of non-kin groups and a more general emphasis of group interests over individual interests (House et al., 2004: p. 462).

The first important result was that the Institutional Collectivism practices scale did not correlate at all to the In-Group Collectivism practices scale (House et al., 2004: 466). Therefore, three different groups can be distinguished. Individualistic cultures, as for example the Netherlands, Switzerland, (West) Germany, England, Australia, and the U.S., had low In-group Collectivism scores and low to medium Institutional Collectivism scores. A group of collectivistic cultures, as for example Georgia, Iran, India, Turkey, Morocco, and Ecuador, had high In-group Collectivism scores and medium to low Institutional Collectivism scores. And a second group of collectivistic cultures, as for example Sweden, South Korea, Japan, Singapore, New Zealand, and Denmark, had high Institutional Collectivism scores. The Scandinavian countries and New Zealand in this group had low In-Group Collectivism scores, whereas the Buddhist countries (also including China and Taiwan) had also high In-Group Collectivism scores. Japan was here an exception, because it had a medium In-Group Collectivism score (House et al., 2004: 468f.).

Furthermore, Institutional Collectivism practices had a significant positive correlation to economic prosperity, public sector support for prosperity, competitiveness, and success in basic science, whereas In-Group Collectivism practices 
had a significant negative correlation to those four variables (House et al., 2004: 482f.).

Those empirical findings support my theoretical analysis, because they show that it is important to separate two types of collectivistic cultures: In-Group Collectivistic cultures that are not very progressive and which correspond to traditional cultures in my terminology, and Institutional Collectivistic cultures that are progressive and which I have called modern relational cultures.

It is worth mentioning that Institutional and In-Group Collectivism practices were correlated to several other dimensions in the GLOBE study (House et al., 2004: 472f.). In other words, a culture's orientation towards individualism and the two types of collectivism explains several other characteristic elements of this culture. And since this orientation towards individualism and collectivism can be regarded as an expression of how the social-order problem is solved in this culture, my proposed theory would describe a key element of the formation of cultures.

\section{Conclusion}

Based on an analysis of the classical social order problem in the works of Thomas Hobbes and Talcott Parsons, I was able to show that Hobbes and Parsons focussed on different aspects of the problem. The fact that both approaches complement each other allowed me to synthesize their theories. I derived out of their arguments three major questions: 1) What is the problem in the interaction structure (the situation analysis)? Which motives can solve the interaction problem (the motivation analysis)? And into which institution can the interaction problem be transformed (the institution analysis)?

In the situation analysis, I argued that game theorists were unable to prove under realistic assumptions that rational actors would play cooperative in prisoners' dilemmas. As a result, I pointed out in the motivation and institution analyses that on the other hand specific motives and institutional settingswhich are usually rejected by game theorists as trivial solutions-can explain cooperation in prisoners' dilemmas. Furthermore, I argued that those solutions form patterns that could be interpreted as ideal-typical solutions of the social order, which again could be used as a scheme to classify cultures based on how they create cooperation. This scheme of interpretation for cultures would allow the empirical test of conflicting theories about the development of cultures (e.g. Parsons's differentiation theory or the nihonjinron). And finally, I have shown that already empirical studies exist that support my distinction between different types of modern cultures. We were, however, not able to see this, because we lacked the theoretical framework to interpret those empirical results.

\section{Conflicts of Interest}

The authors declare no conflicts of interest regarding the publication of this paper. 


\section{References}

Alexander, J. C. (1983). Theoretical Logic in Sociology. Berkeley, CA: University of California Press.

Alexander, J. C. (1990). Analytic Debates. In J. C. Alexander, \& S. Seidman (Eds.), Culture and Society (pp. 1-27). Cambridge: Cambridge University Press.

Alexander, R. W. (1971). The Myth of Power: Hobbes's Leviathan. Journal of English and Germanic Philology, 70, 31-50.

Ball, T. (1985). Hobbes' Linguistic Turn. Polity, 17, 739-760. https://doi.org/10.2307/3234572

Ballestrem, K. G. (1983). Vertragstheoretische Ansätze in der politischen Philosophie. Zeitschrift für Politik, 30, 1-17.

Barry, B. (1990). Political Argument. New York/London: Harvester Wheatsheaf.

Baurmann, M. (1996). Der Markt der Tugend. Tübingen: Mohr.

Becker, G. S. (1976). Altruism, Egoism, and Genetic Fitness. Journal of Economic Literature, $14,817-826$.

Becker, G. S. (1981). A Treatise on the Family. Cambridge, MA/London: Harvard University Press.

Binmore, K. (2007). Playing for Real. Oxford: Oxford University Press. https://doi.org/10.1093/acprof:oso/9780195300574.001.0001

Collard, D. (1978). Altruism and Economy. Oxford: Robertson.

Damme, E. V. (1987). Stability and Perfection of Nash Equilibria. Berlin: Springer. https://doi.org/10.1007/978-3-642-96978-2

Fender, J. (1995). Altruism, Ethics and Economics. In S. Brittan, \& A. Hamlin (Eds.), Market Capitalism and Moral Values (pp. 120-136). Aldershot/Brookfield: Elgar.

Forges, F. (1992). Repeated Games of Incomplete Information: Non-Zero-Sum. In R. J. Aumann, \& S. Hart (Eds.), Handbook of Game Theory (Vol. 1, pp. 155-177). Amsterdam: North Holland. https://doi.org/10.1016/S1574-0005(05)80009-8

Forsyth, M. (1994). Hobbes's Contractarianism. In D. Boucher, \& P. Kelly (Eds.), The Social Contract from Hobbes to Rawls (pp. 35-50). London/New York: Routledge. https://doi.org/10.4324/9780203392928_chapter_2

Gauthier, D. (1969). The Logic of Leviathan. Oxford: Clarendon.

Gauthier, D. (1979). Thomas Hobbes: Moral Theorist. Journal of Philosophy, 76, 547-559. https://doi.org/10.2307/2025550

Goode, W. J. (1960). Norm Commitment and Conformity to Role-Status Obligations. American Journal of Sociology, 66, 246-258. https://doi.org/10.1086/222876

Hampton, J. (1985). Hobbes's State of War. Topoi, 4, 47-60. https://doi.org/10.1007/BF00138648

Hampton, J. (1992). Hobbes and Ethical Naturalism. Philosophical Perspectives, 6, 333-353. https://doi.org/10.2307/2214251

Hobbes, T. (1839). Leviathan, English Works, Vol. 3. London: Bohn.

Hobbes, T. (1841). Philosophical Rudiments Concerning Government and Society, English Works, Vol. 2. London: Bohn.

Hobbes, T. (1969). The Elements of Law. London: Cass.

Hofstede, G. (2001). Culture's Consequences (2nd ed.). Thousand Oaks, CA: Sage.

Holler, M. J., \& Illing, G. (1996). Einführung in die Spieltheorie. Berlin: Springer. https://doi.org/10.1007/978-3-662-06877-9 
Hood, F. C. (1964). The Divine Politics of Thomas Hobbes. Oxford: Clarendon.

House, R. J., Hanges, P. J., Javidan, M., Dorfman, P. W., \& Gupta, V. (2004). Culture, Leadership, and Organizations: The GLOBE Study of 62 Societies. Thousand Oaks, CA: Sage.

Inglehart, R. (1990). Culture Shift in Advanced Industrial Society. Princeton, NJ: Princeton University Press. https://doi.org/10.1515/9780691186740

Joas, H. (1973). Die gegenwärtige Lage der soziologischen Rollentheorie. Frankfurt: Athenäum.

Kassab, E. S. (1991). The Theory of Social Action in the Schutz-Parsons Debate. Freiburg: Universitätsverlag Freiburg.

Kateb, G. (1989). Hobbes and the Irrationality of Politics. Political Theory, 17, 355-391. https://doi.org/10.1177/0090591789017003001

Kavka, G. S. (1983a). Hobbes's War of All against All. Ethics, 93, 291-310. https://doi.org/10.1086/292435

Kavka, G. S. (1983b). Right Reason and Natural Law in Hobbes's Ethics. Monist, 66, 120-133. https://doi.org/10.5840/monist198366111

Kliemt, H. (1990). The Costs of Organizing Social Cooperation. In M. Hechter, K.-D. Opp, \& R. Wippler (Eds.), Social Institutions (pp. 61-80). Berlin/New York: de Gruyter. https://doi.org/10.4324/9781351328807-5

Lockwood, D. (1956). Some Remarks on “The Social System”. British Journal of Sociology, 7, 134-146. https://doi.org/10.2307/587854

Münch, R. (1982). Theorie des Handelns. Frankfurt: Suhrkamp.

Murphy, A. R. (1997). The Uneasy Relationship Between Social Contract Theory and Religious Toleration. Journal of Politics, 59, 368-392. https://doi.org/10.1017/S0022381600053494

Oakeshott, M. J. (1946). Hobbes on Civil Association. Oxford: Blackwell.

Olson, M. (1965). The Logic of Collective Action. Cambridge, MA: Harvard University Press.

Parsons, T. (1951). The Social System. Glencoe: Free Press.

Parsons, T. (1971). The System of Modern Societies. Englewood Cliffs, NJ: Prentice-Hall.

Parsons, T. (1986). Aktor, Situation und normative Muster. Frankfurt: Suhrkamp.

Raphael, D. D. (2004). Hobbes: Morals and Politics. London/New York: Routledge.

Rawls, J. (1971). A Theory of Justice. Cambridge, MA: Harvard University Press.

Schmitt, C. (1937). Der Staat als Mechanismus bei Hobbes und Descartes. Archiv für Rechts-und Sozialphilosophie, 30, 622-632.

Schwartz, S. H. (1992). Universals in the Content and Structure of Values. In M. Zanna (Ed.), Advances in Experimental Social Psychology (pp. 1-66). New York: Academic Press. https://doi.org/10.1016/S0065-2601(08)60281-6

Skidmore, W. (1975). Theoretical Thinking in Sociology. Cambridge: Cambridge University Press.

Skyrms, B. (1990). The Dynamics of Rational Deliberation. Cambridge, MA: Harvard University Press.

Strauss, L. (1950). On the Spirit of Hobbes' Political Philosophy. Revue Internationale de Philosophie, 4, 405-431.

Taylor, A. E. (1938). The Ethical Doctrine of Hobbes. Philosophy, 13, 406-424.

https://doi.org/10.1017/S0031819100014194 
Taylor, M. (1976). Anarchy and Cooperation. London/New York: Wiley \& Sons.

Triandis, H. C. (1989). The Self and Social Behavior in Different Cultural Contexts. Psychological Review, 96, 269-289. https://doi.org/10.1037/0033-295X.96.3.506

Vinken, H., Soeters, J., \& Ester, P. (2004). Cultures and Dimensions. In H. Vinken, J. Soeters, \& P. Ester (Eds.), Comparing Cultures (pp. 5-27). Leiden: Brill.

Voss, T. (1985). Rationale Akteure und soziale Institutionen. München: Oldenbourg. https://doi.org/10.1515/9783486824063

Warrender, H. (1962). Hobbes's Conception of Morality. Revista Critica di Storia della Filosofia, 17, 434-449.

Watkins, J. W. N. (1955). Philosophy and Politics in Hobbes. Philosophical Quarterly, 5, 125-146. https://doi.org/10.2307/2217139

Wenzel, H. (1986). Einleitung. In T. Parsons (Ed.). Aktor, Situation und Normative Muster (pp. 7-58). Frankfurt: Suhrkamp.

Zeitlin, I. M. (1973). Rethinking Sociology. New York: Meredith. 